\title{
Human Factors Evaluation in Ship Design and Operation: An Case Study in Norwegian Sea
}

\author{
Vincentius Rumawas $^{1, a,{ }^{*}}$, Bjørn E. Asbjørnslett ${ }^{2}$ and Christian A. Klöckner² \\ ${ }^{1}$ Department of Ocean Engineering, Faculty of Marine Technology, ITS, Surabaya, Indonesia \\ ${ }^{2}$ Department of Marine Technology, Norwegian University of Science and Technology, Trondheim, \\ Norway \\ a.vrumawas@oe.its.ac.id \\ *corresponding author
}

Keywords: comfort class, human factors, motion criteria, motion induced interruption (MII), motion sickness incidence (MSI), noise criteria, safety at sea, ship design and operation.

Abstract: Research demonstrated that the majority of accidents at sea were triggered by human errors. While working as seafarers is demanding, human factors were hardly addressed in ship design. It seems that there was a mismatch between the knowledge of ship design and the needs to consider human factors in reality. The implementation of human factors in ships is rather limited; i.e. within the safety-related issues. This research investigated human factors in ship design and operation by using empirical methods. Surveys were performed on platform supply vessels in Norwegian Sea where seafarers' evaluation, sleeping behaviour, conditions and seafarers' performance were recorded. Noise and motions were measured using a sound level meter and an accelerometer respectively. Data collections were done in summer as well as in winter. Two reports were published and summarized in this paper. Results were compared with the criteria. Discrepancies were identified. It can be concluded that some of the criteria were not adequate to ensure safety, moreover comfort. Specific improvements are recommended with respect to motion, slamming and noise criteria. Human factors structural model is developed and can be used to explain seafarers' condition and performance on board. Due to the small number of samples, generalization of this research is limited for a specific population.

\section{Introduction}

Most accidents at sea were mainly caused by human error and other human related factors [1]. Inadequate design was named as one the source triggering human actions [2]. Human fatigue is verified to induce lack of situation awareness and human errors which then leading to accidental events $[1,3]$. Fatigue is influenced by issues such as lack of sleep, poor quality of sleep, insufficient rest time, noise, vibration, ship movement, and excessive work load [4]. Motion and noise were also identified as main causes of sleep interruptions [5]. Motion can reduce operator's performance, and thus safety [6]. Motion of a vessel at sea will interfere with the crew's balance, causing motion- 
induced interruptions (MII), increasing the energy expenditure and increasing the levels of fatigue, drowsiness and dizziness. Motion also causes stomach awareness, induces motion sickness incidences (MSI) and causes vomiting incidence [5, 7]. In this research, human factors in ship design and operation were investigated using empirical studies.

Guidance of how to mitigate and manage fatigue at sea during operations has been published by relevant bodies $[3,8,9]$. Several measures are proposed, including sleeping pattern, watch schedule, environmental manipulation, workload management and dietary arrangement. Remedial measures have been identified in ship design; including comfortable accommodations, minimizing noise and vibration, improving indoor climate and providing better working facilities.

Several guides and standards on vessels' habitability and comfort are available and ready to be implemented. Improving habitability and comfort level on a vessel should induce better sleep and rest for the personnel, hence increase performance.

As an example, Det Norske Veritas (DNV) (now: DNV GL) provides an additional class which is called comfort (COMF) class. It is split into two: noise and vibration (COMF-V notation) and indoor climate (COMF-C notation) [10]. There are three levels of comfort in COMF-V: 1 (highest), 2 (medium) and 3 (acceptable). Table 1 0demonstrates samples of noise criteria on some locations on the vessel. It is mentioned in the text that measurements shall be made in accordance with ISO 2923 standard [11].

The International Maritime Organization (IMO) has put a foundation to address ergonomics and work environment in order to reduce accidents and human errors on ships [12]. In a separate document, IMO also publishes a procedure on noise levels on board ships [13]. Table 2 shows samples of criteria for maximum noise level on ships according to IMO's documentation.

Table 1: Crew Accommodation Noise Levels in dB(A) [10]

\begin{tabular}{|l|c|c|c|}
\hline \multirow{2}{*}{ Locations } & \multicolumn{3}{c|}{ Comfort rating nr (crn) } \\
\cline { 2 - 4 } & 1 & 2 & 3 \\
\hline Wheelhouse & 60 & 60 & 65 \\
\hline Crew cabins & 50 & 55 & 60 \\
\hline Crew public spaces & 55 & 60 & 65 \\
\hline Engine control room & 70 & 70 & 75 \\
\hline Open deck recreation & 70 & 70 & 75 \\
\hline
\end{tabular}

Table 2: Noise Levels On Board Ships [13]

\begin{tabular}{|l|c|}
\hline \multicolumn{1}{|c|}{ Noise level limits } & $\mathrm{dB}(\mathrm{A})$ \\
\hline Machinery spaces (continuously manned & 90 \\
\hline Machinery spaces (non-continuously manned) & 110 \\
\hline Machinery control rooms & 75 \\
\hline Workshops & 85 \\
\hline Non-specified workspaces & 90 \\
\hline Normally unoccupied spaces & 90 \\
\hline
\end{tabular}

Despite vibration, noise and indoor climate, documents from classification societies and IMO do not cover criteria for ship motion. Two main references for ship motions criteria are North Atlantic Treaty Organization (NATO) Standardization Agreement (STANAG) 4154 [14] and Nordic Cooperative Organization for Applied Research [15], specifying maximum roll amplitude, pitch amplitude, vertical and lateral acceleration. Table 3 and Table 4 show operability criteria set by the two references. Opresents the MII risk levels used by Graham (1990) [16]. 
Table 3: Personnel criteria limits [14]

\begin{tabular}{|l|c|c|}
\hline \multicolumn{1}{|c|}{ Recommended criteria } & Limit & Location \\
\hline Motion sickness incidence (MSI) & $20 \%$ of crew @ 4 hours & Task location \\
\hline Motion induced interruption (MII) & $1 / \mathrm{min}$ & Task location \\
\hline Default criteria & \multicolumn{2}{|c|}{ Root meas square (RMS) } \\
\hline Roll & $4^{\mathrm{o}}$ & \\
\hline Pitch & 1.5 & \\
\hline Vertical acceleration & $0.2 \mathrm{~g}$ & Bridge \\
\hline Lateral acceleration & $0.1 \mathrm{~g}$ & Bridge \\
\hline
\end{tabular}

Table 4: Operability and Criteria Set For Ships [15]

\begin{tabular}{|c|c|c|c|}
\hline General operability limiting criteria for ships & \multicolumn{3}{|c|}{ For merchant ships } \\
\hline Vertical acceleration RMS, bridge & \multicolumn{3}{|c|}{$0.15 \mathrm{~g}$} \\
\hline Lateral acceleration RMS, bridge & \multicolumn{3}{|c|}{$0.12 \mathrm{~g}$} \\
\hline Roll & \multicolumn{3}{|c|}{$6^{\circ} \mathrm{RMS}$} \\
\hline $\begin{array}{l}\text { Probability of slamming } \\
\text { (for up } 100 \mathrm{~m} \text { long vessel) }\end{array}$ & \multicolumn{3}{|c|}{0.03} \\
\hline Criteria regarding acceleration and roll & Vert acc & Lat acc & Roll \\
\hline Light manual work (RMS) & $0.20 \mathrm{~g}$ & $0.10 \mathrm{~g}$ & $6.0^{\circ}$ \\
\hline Heavy manual work (RMS) & $0.15 \mathrm{~g}$ & $0.07 \mathrm{~g}$ & $4.0^{\circ}$ \\
\hline Intellectual work (RMS) & $0.10 \mathrm{~g}$ & $0.05 \mathrm{~g}$ & $3.0^{\circ}$ \\
\hline Transit passengers (RMS) & $0.05 \mathrm{~g}$ & $0.04 \mathrm{~g}$ & $2.5^{\circ}$ \\
\hline Cruise liner (RMS) & $0.02 \mathrm{~g}$ & $0.03 \mathrm{~g}$ & $2.0^{\circ}$ \\
\hline
\end{tabular}

Table 5: MII risk levels [16]*)

\begin{tabular}{|l|c|}
\hline \multicolumn{1}{|c|}{ Risk level } & MII's per minute \\
\hline Possible & 0.1 \\
\hline Probable & 0.5 \\
\hline Serious & 1.5 \\
\hline Severe & 3.0 \\
\hline Extreme & 5.0 \\
\hline
\end{tabular}

*) original source: Baitis, A.E., T.R. Applebee and T.M. McNamara: "Human Factor Considerations Applied to Operations of the FFG-8

Exploratory surveys on offshore supply vessels (OSVs) were performed before this research Two COMF class vessels were picked as the samples [17]. The surveys revealed problems like high pitch disturbing noise in the cabin, noisy deck, excessive rolling motion and slamming and pitching. Sometimes, people also experience stomach awareness, gets seasick and even vomits.

This research was designed to answer two questions:

1. Are the existing criteria of human factors in ship design relevant and adequate?

2. What factors considerably influence seafarers' performance at sea?

Two reports have been published in Naval Engineers Journal $[18,19]$ and summarized here. The first report covers the introduction, methodology and the technical aspects of the research that includes measurements of the environmental conditions, noise and motion combined with some relevant evaluations. The second report covers the multivariate analyses regarding the seafarers' condition and performance and the liable underlying factors. 


\section{Research Design}

Figure 1 shows the research design developed to answer the questions raised above. Before sailing, vessels receive information which offshore facilities they are about to visit. Weather forecasts are provided including wind speed and wave characteristics (significant wave height, Hs and peak period, $T p$ ). During the voyage, the crew records the environmental conditions in the logbook. The ship responses in the form of motions are measured together with the noise levels at several locations on the vessel. Surveys are conducted in summer and in winter. Effects of the environmental condition to seafarers' performance are investigated as well as how the effects are moderated by the ship design. Seafarer' performance is assessed in terms of sleeping behaviour, symptoms on the watch and performance on watch. Sleeping behaviour covers the quality and duration of the sleep and sleep related problems encountered by the seafarers before they go to watch. Symptoms on watch consist of ten aspects including fatigue, tiredness, sleepiness, MII or loss of balance, and stomach awareness or MSI. Performance on the watch is evaluated in terms of cognitive activity, motoric activity and communication. Sleep problems are divided into two: shiprelated and non-ship related problems. Watch time and work shift are also included in the model as they may influence performance.

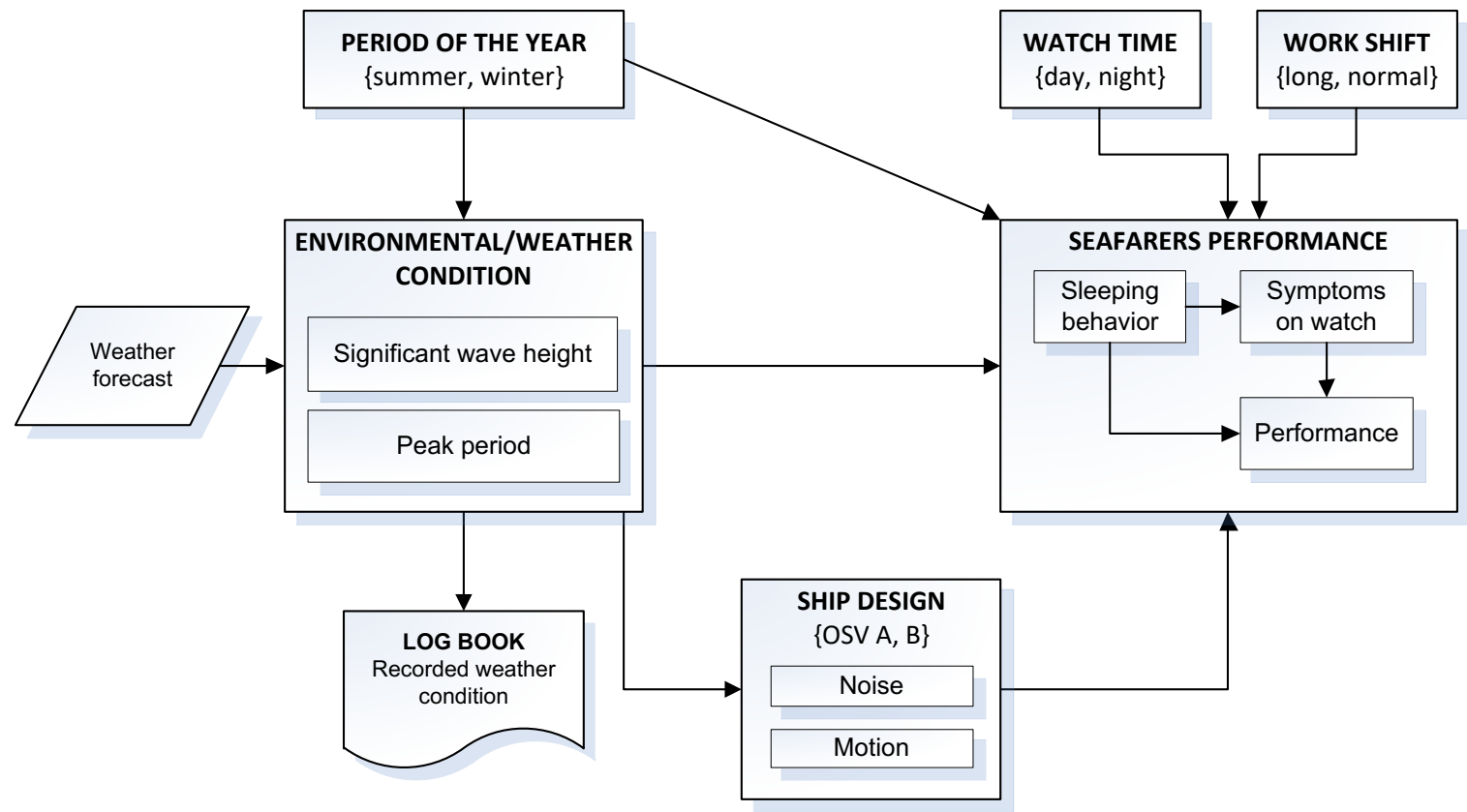

Figure 1: Research Design

\section{Methodology}

The field surveys were conducted to collect different types of information simultaneously.

\subsection{Samples and Data Collection}

Two offshore supply vessels (OSVs) in the Norwegian Sea were picked as the object for the study (Figure 2). Surveys were conducted in two periods: July 2011 and October 2011. Both vessels were visited alternately. OSV A was built with the superstructure on the bow. This design represents 
most of OSVs in the world. OSV B was built with superstructure at the aft. This design resembles most container and bulk cargoes. Both vessels carry DNV COMF-V(3) notation.


Figure 2: Offshore Supply Vessels Used for The Study [17]

\subsection{Environmental condition}

Weather forecasts provide information concerning the upcoming environmental conditions. Data for a particular location at a particular time could be downloaded from the company's website. During the voyage, the officers on the bridge also monitored the true wind speed and recorded the sea state including the approximate wave heights. Anemometer was utilized to measure wind speed, while the wave height was observed visually.

\subsection{Noise}

Noise measurements were performed in accordance with the procedures described in ISO 2923 [11] and ISO 20283-2 [20]. The standards specify the type and class of instrument, setting and position of the instrument, and length of each measurement. In this research class 2 sound level meter Bruel \& Kjaer Type 2236 was used. A-frequency-weighting was applied.

\subsection{Motion}

A product of Analog Devices, ADIS16364 was used to measure ship motion. It is a high-precision tri-axis inertial sensor which can measure tri-axis angular velocities (roll, pitch and yaw) and triaxis translational accelerations (surge, sway and heave) at the same time. The sensor was located in the cabin, mounted on the floor facing forward parallel to the ship's longitudinal axis and connected to a personal computer by means of a universal serial bus (USB) cable.

\subsection{Questionnaires}

A form was developed based on the NATO questionnaire [5, 21], and modified according to the research context. The seafarers were asked to complete the form after every watch. A detail description of the questionnaire can be found in [19] and [22]. 


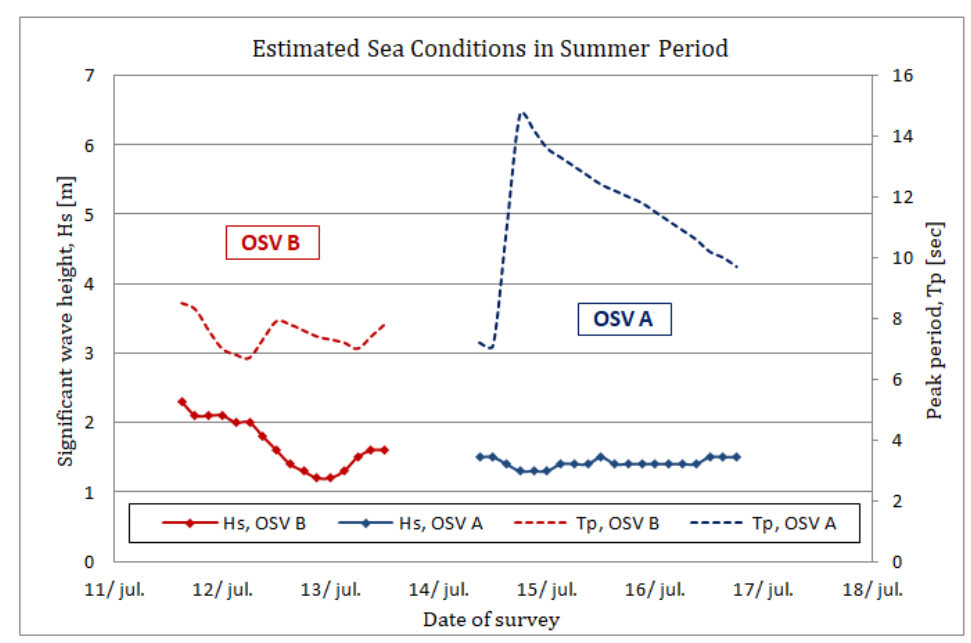

Figure 3: Weather Forecast During the Survey in Summer

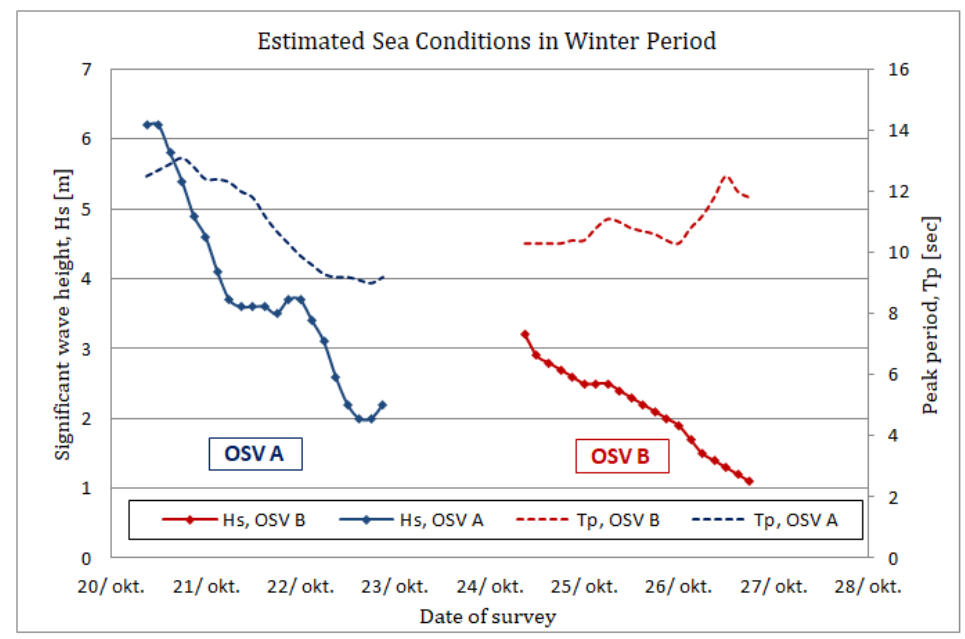

Figure 4: Weather Forecast During the Survey in Winter

\section{Results}

In summer, weather is typically nice, the wind is light, and the sea is relatively calm. On the contrary, in winter the sea tends to be harsh, characterized by strong wind and high waves. Sometimes when the wind speed is too high and the sea is too harsh, vessels are not allowed to set sail. They are called in to shelter and wait until the sea has become more 'friendly'.

\subsection{Weather forecasts and ships' $\log$}

Figure 3 and Figure 4 show $H s$ and $T p$ predictions along the trip during the survey. In summer, OSV B experienced moderate sea (sea state 4), while OSV A went through smooth sea (sea state 2). In winter, OSV A had sea state 5 to 6 (rough to very rough), while OSV B registered sea state 4 (moderate). 


\subsection{Noise level measurement}

Results of noise measurement are presented in Table 6. All conditions satisfy the criteria set by Table 1 (DNV) as well as Table 2 (IMO). The disturbing, high pitch noise caused by DP, impulsive noise caused by slamming cannot be captured nor reflected by the procedures specified [10] [13].

Table 6: Noise Level Measurement Results in $\mathrm{dB}(\mathrm{A})$

\begin{tabular}{|l|c|c|c|c|}
\hline \multicolumn{1}{|c|}{$\begin{array}{c}\text { Locations on the vessel } \\
\text { (conditions) }\end{array}$} & \multicolumn{2}{c|}{ Summer } & \multicolumn{2}{c|}{ Winter } \\
\cline { 2 - 5 } & OSV A & OSV B & OSV A & OSV B \\
\hline Bridge & & 59.7 & 59.4 & 57.5 \\
Bridge (with moderate music) & 63.2 & 61.4 & & \\
Engine control room (normal) & 57.9 & 66.7 & 58.9 & 57.7 \\
Engine control room (with additional noises) & 71.2 & & & 61.7 \\
Engine room (main engines) & 104.6 & 105.9 & 103.8 & 104.9 \\
Engine room (bow thrusters) & 96.5 & 101.7 & 102.3 & 91.4 \\
Engine room (bow thrusters. non-working) & 93.1 & 73.2 & 91.7 & 70.0 \\
Cargo Deck & 71.0 & 85.9 & 68.5 & 83.9 \\
Dirty mess. workshop & 67.9 & 77.7 & 64.6 & 78.8 \\
Cabin (normal) & 40.9 & 45.4 & 42.4 & 41.8 \\
Cabin (on DP) & 49.7 & & 56.7 & \\
Cabin (deck machineries. windlass operating) & & & 49.5 & \\
Cabin (sailing in high seas with slamming) & & & 54.1 & \\
\hline
\end{tabular}

\subsection{Ship motions}

Summary of statistical analyses are presented in Table 7. The overall motions of the ships during the survey are presented in Figure 5.

The average magnitude of the motion during each survey is presented in terms of RMS. Maximum values are also provided for reference. The highest RMS roll motion measured in our survey is $0.54^{\circ}$. The maximum roll motion recorded was $1.934^{\circ}$. The criterion for cruise liner is $2^{\circ}$ RMS. The highest RMS accelerations measured is $0.065 \mathrm{~g}$ (lateral) and $0.149 \mathrm{~g}$ (vertical). The operability criteria for light manual work are set $0.10 \mathrm{~g}$ and $0.20 \mathrm{~g}$ for lateral and vertical accelerations respectively. The criteria are perfectly met at all time during our survey, including in sea state 5 to 6 , where the wave heights reach more than $10 \mathrm{~m}$.

Table 7: Summary Results of Ship Motions

\begin{tabular}{|c|c|c|c|c|c|c|c|c|c|}
\hline \multirow{2}{*}{ OSV } & \multirow{2}{*}{ Survey } & \multicolumn{2}{|c|}{ Roll in $^{\circ}$} & \multicolumn{2}{c|}{ Pitch in $^{\circ}$} & \multicolumn{2}{c|}{$\begin{array}{c}\text { Lateral } \\
\text { acceleration, g }\end{array}$} & \multicolumn{2}{c|}{$\begin{array}{c}\text { Vertical } \\
\text { acceleration, g }\end{array}$} \\
\cline { 2 - 11 } & & RMS & Max & RMS & Max & RMS & Max & RMS & Max \\
\hline \multirow{2}{*}{$\mathrm{A}$} & Summer & 0.163 & 0.948 & 0.127 & 0.828 & 0.014 & 0.098 & 0.026 & 0.153 \\
\cline { 2 - 11 } & Winter & 0.355 & 1.934 & 0.483 & 3.073 & 0.038 & 0.263 & 0.097 & 0.562 \\
\hline \multirow{2}{*}{$\mathrm{B}$} & Summer & 0.124 & 0.701 & 0.269 & 1.882 & 0.016 & 0.126 & 0.024 & 0.142 \\
\cline { 2 - 10 } & Winter & 0.127 & 0.870 & 0.151 & 1.419 & 0.015 & 0.124 & 0.020 & 0.111 \\
\hline
\end{tabular}




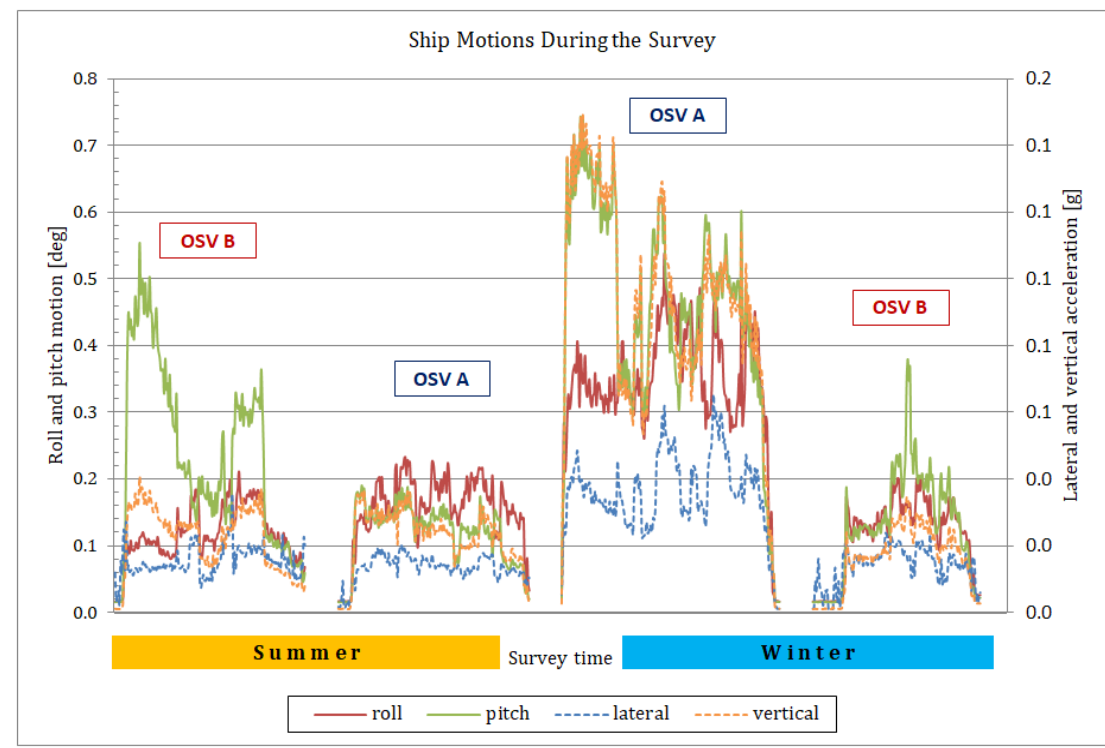

Figure 5: Ship Motions During the Survey

\subsection{Questionnaires}

As many as 188 forms were completed and returned. There were 17-18 personnel on each OSV on every visit. In general, the crew on OVSs can be divided into three groups according to their watch schedule; two groups work in pairs in normal shift and one group works long shift. Detailed results of the questionnaires can be found in [19].

Sleeping problems is found to vary significantly across OSVs, $\chi^{2}(2, \mathrm{~N}=164)=8.033, p<.05$ and across seasons, $\chi^{2}(2, \mathrm{~N}=164)=8.194, p<.05$, but watch time and shifts do not bring similar effect; $\chi^{2}$ $(2, \mathrm{~N}=164)=0.312, p>.10$ and $\chi^{2}(2, \mathrm{~N}=164)=4.588, \mathrm{p}>.10$ respectively. Slamming is revealed as the most frequently mentioned sleep causal problem (13.8\%). Noise $(10.6 \%)$ and ship motion $(9.6 \%)$ are next in the list, and temperature or indoor climate is the forth $(8.5 \%)$. Then, toilet visit $(7.4 \%)$ is the most reported among the non-ship-related sleep causal problems.

In general the crew experience worse symptoms in winter: significantly more physically tired, $\mathrm{F}(1,170)=3.931, p<.05$, experience more MIIs, $\mathrm{F}(1,165)=5.620, p<.05$ and experience more stomach awareness, nausea, leading to vomiting, $\mathrm{F}(1,164)=3.649, p<.10$.

The research found that the overall symptoms experienced by the crew differ significantly across different OSV design, $\mathrm{F}(1,186)=6.871, p<.001$. A highly significant variation on MII is also revealed, $\mathrm{F}(1,165)=8.346, p<0.01$. The difference on MSI across OSVs is rather marginal, $\mathrm{F}(1$, $164)=3.008, p<0.10$. Furthermore, there is no significant difference on the tiredness found across OSVs, $\mathrm{F}(1,170)=2.638, p>0.10$.

The crew on both OSVs reported lower performance in winter compare to the survey in summer $\mathrm{F}(1,186)=12.844, p<.001$. All the variations exposed on OSV A are statistically confirmed $(p<.05)$, however on OSV B the differences are insignificant $(p>.10)$. The difference on the overall performance across OSVs is marginally significant, $\mathrm{F}(1,186)=3.90, p<.10$. No difference in performance is found across watch time and across work shifts $(p>.10)$. However, seafarers who work in long shift report better reaction time $(\mathrm{M}=4.30, \mathrm{SD}=.637)$ compare to those who work in normal shift $(\mathrm{M}=4.09, \mathrm{SD}=.638), \mathrm{F}(1,172)=3.123, p<.10$.

The research shows that there is no significant variation in seafarers' performance across OSVs, across watch time, nor work shifts $(p>10)$. On the contrary, the variation across OSVs in winter is 
highly significant in motoric activities, $\mathrm{F}(1,80)=8.513, p<.01$ and thus in amount of tasks completed, $\mathrm{F}(1,80)=8.457, p<.01$.

Issues encountered by the seafarers during their watch were summed up and classified into 'shiprelated' and 'operational-related' problems. Ship-related problem consists of ship motion, noise, slamming, vibration, bad smell and indoor climate. Operational-related problem includes bad weather, bad visibility, technical problems and operational problems. Ship motion and slamming are tallied as the most frequent problems reported during watch. Bad weather and indoor climate are identified as the third and forth in the rank, before vibration and bad smell.

The research revealed that OSV design bring a highly significant variation to ship motions, $\chi^{2}(1$, $\mathrm{N}=188)=13.858, p<.001$, slamming, $\chi^{2}(1, \mathrm{~N}=188)=17.453, p<.001$, and vibration, $\chi^{2}(1$, $\mathrm{N}=188)=8.142, p<.01$. The effect of design to noise level is confirmed to be significant. $\chi^{2}(1$, $\mathrm{N}=188)=4.425, p<.05$, as well as to indoor climate, $\chi^{2}(1, \mathrm{~N}=188)=6.227, p<.05$.

\section{Analysis}

The relationships between ship motions and how people sleep onboard were investigated. Highly significant correlations between different ship motions to ship-related sleep problems were identified. In contrast, correlations between non-ship related problems and motions were found not significant. Stepwise analysis was applied to pick the strongest motion components that influence sleep. Vertical acceleration and pitch are exposed as the components that truly predict ship-related sleep problems (Adjusted $\mathrm{R}^{2}=.237 ; F_{2,185}=30.040$ and $p=.000$ ) but lateral acceleration and roll motion are eliminated.

Ship motions and sleep quality were significantly correlated. Vertical acceleration was found to be the strongest element for sleep problems $(r=0.477)$ as well as sleep quality $(r=-0.349)$. A stepwise regression was conducted on sleep quality with respect to all four ship-motion components. The result confirms the above findings and verifies vertical acceleration as the only factor to remain in the equation while the others are excluded (Adjusted $\mathrm{R}^{2}=.117 ; F_{1,177}=24.478$, $p=.000)$.

Analysis of covariance (Ancova) method was utilized to investigate the effects of survey period and OSV design on sleep quality. The result validates that the effect of OSVs on sleep quality is highly significant given wave height is controlled, $\mathrm{F}(1,175)=11.372, p<.01$.

Quite the reverse, survey period shows no significant effect on sleep quality, $F(1,175)=.0534$, $p>.10$, given wave height is controlled. No interaction effect is found between survey period and different type of OSVs to sleep quality, $\mathrm{F}(1,175)=0.902, p>.10$.

The analysis shows that sleep amount has a highly significant relationship with vertical acceleration. The relationship of sleep amount and lateral acceleration is also found significant. OSV design has a significant effect on sleep amount when $\mathrm{Hs}$ is controlled, $\mathrm{F}(1,172)=5.836$, $p<.05)$. The seafarers' overall conditions were investigated further using stepwise regression analysis. Ship-related sleep problems, sleep amount and non-ship related sleep problems are found as significant influencing factors for the overall conditions (Adjusted $\mathrm{R}^{2}=.297 ; F_{3,170}=25.386$, $p=.000$ ), while the others are excluded.

Using similar procedures and independent variables it was revealed that tiredness is significantly affected by sleep quality, sleep amount, ship-related sleep problems and non-ship related sleep problems. Vertical acceleration during watch is found to affect MII (Adjusted $\mathrm{R}^{2}=.110$; $\left.F_{1,165}=21.499, \beta=-.340, p=.000\right)$. The correlation index between MII reported by the crew in this survey and the index calculated using the existing code [16] is rather low, $r=-0.184, p=.018$.

MSI has a very significant correlation with pitch, $r=-0.405, p<.001$ and roll motion, $r=-0.400$, $p<.001$. Stepwise shows that pitch is the only motion component significantly causing stomach 
awareness, nausea leading to vomiting (Adjusted $\mathrm{R}^{2}=.159 ; F_{1,164}=32.189, \beta=-.405, p=.000$ ). A very significant but rather low correlation is found between stomach awareness reported by the crew and the predicted MSI index calculated for 8-hour exposure [23, 24] $r=-0.261, p=.001$.

A model is developed to describe the connections between variables of interest in this research. Structural equation modelling (SEM) is used, specifically path analysis. Mplus 6.1 software was utilized to run the analysis. Figure 6 shows the final model. The model fit is acceptable, $\chi^{2}=27.284$, $d f=15, p=.027, C F I=.963, T L I=.919, R M S E A=.066[.022$.105], $S R M R=.044)$.

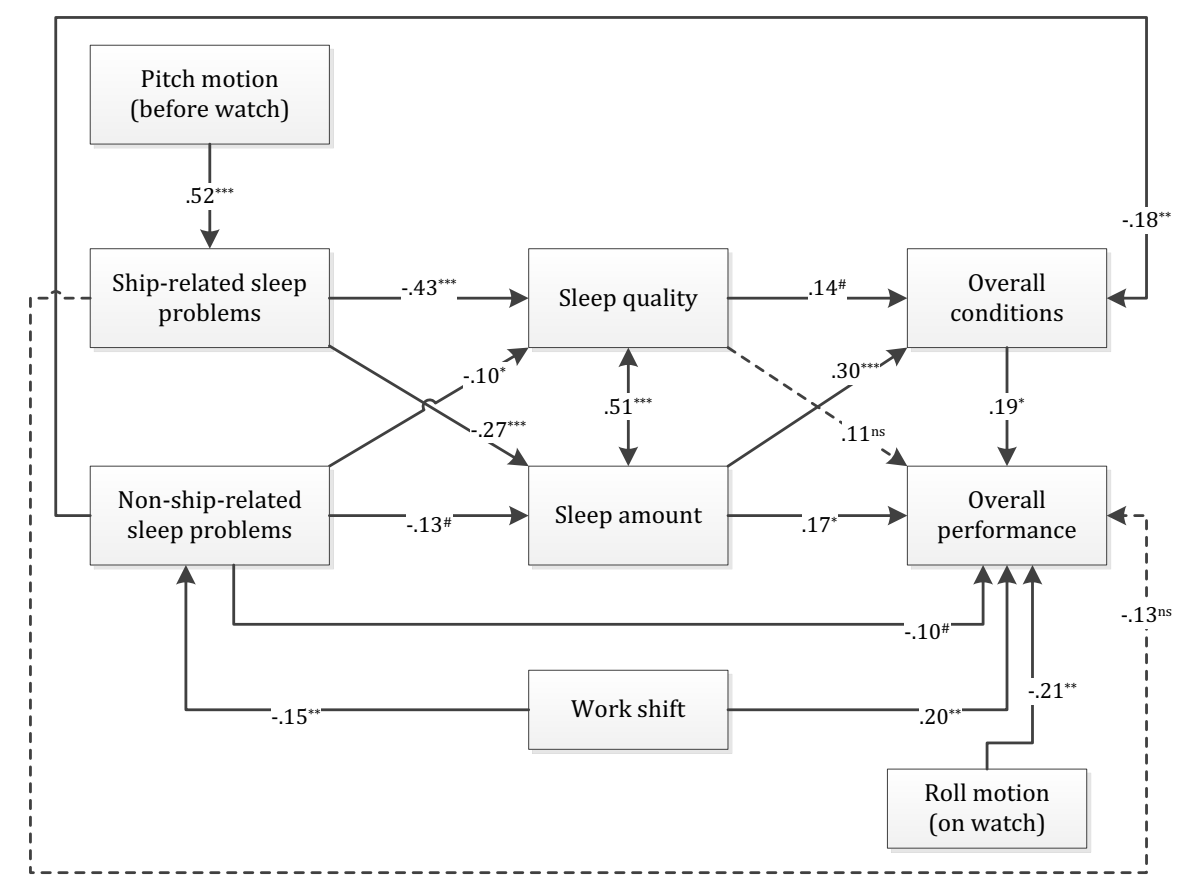

Figure 6: Path Analysis on Human Factors Of OSV Operations $(* * * p<.001 ; * * p<.01 ; * p<.05$; \# $p<.10^{n s}$ not significant)

\section{Conclusion}

The implementation of human factors in ship design and operation has been evaluated. Two comfort class offshore supply vessels were taken as studied. From the research it can be concluded that the existing standards are inadequate for the target population. The existing noise criteria do not reflect comfort. Disturbing noises such as impulsive noise, high pitch noise, squeaking noise and hammering noise are not covered by the standard. The existing motions criteria including MII and slamming are considerably lenient for the vessels surveyed in this study. A path analysis shows that seafarers' wellbeing is influenced by how long and how well they slept before watch, which in turn is mostly influenced by noise, vibration and motion.

\section{References}

[1] Baker, C.C. and D.B. McCafferty, Accident Database Review of Human-element Concerns: What Do the Results Mean for Classification?, in International Conference on Human Factors in Ship Design, Safety and Operation. 2005, Royal Institution of Naval Architects: London. p. 65-71.

[2] Baker, C.C. and A.K. Seah, Maritime Accidents and Human Performance: the Statistical Trail, in MARTECH 2004. 2004: Singapore. 
[3] Alert!, Time to wake up to the consequences of Fatigue, in Alert! The International Maritime Human Element Bulletin. 2007, The Nautical Institute.

[4] Allen, P., E. Wadsworth, and A. Smith, eds. The relationship between recorded hours of work and fatigue in seafarers. Contemporary Ergonomics, ed. P.D. Bust. 2006.

[5] Haward, B.M., C.H. Lewis, and M.J. Griffin, Motions and crew responses on an offshore oil production and storage vessel. Applied Ergonomics, 2009. 40(5): p. 904-914.

[6] Ross, J.M., Human Factors Considerations for Marine Vehicle Design, in International Conference on Human Factors in Ship Design, Safety and Operation. 2009, Royal Institution of Naval Architects: London. p. 29-37.

[7] Stevens, S.C. and M.G. Parsons, Effects of Motion at Sea on Crew Performance: A Survey. Marine Technology, 2002. 39: p. 29-47.

[8] ITF Seafarers. Fatigue. 2012 29.01.2015]; Available from: http://www.itfseafarers.org/ITI-fatigue.cfm.

[9] Smith, A., P. Allen, and E. Wadsworth, Seafarer Fatigue: The Cardiff Research Programme. 2006, Cardiff, UK: Centre for Occupational and Health Psychology, Cardiff University.

[10] DNV, Rules for Classification of Ships Comfort Class, in Special Service and Type Additional Class 2009, Det Norske Veritas: Høvik, Norway.

[11] ISO, Acoustics - Measurement of Noise On Board Vessels. 1996, The International Organization for Standardization: Geneva, Switzerland.

[12] IMO, Framework for Consideration of Ergonomics and Work Environment, in MSC-MEPC.7/Circ.3, I.M. Organization, Editor. 2006: London.

[13] IMO, Code on Noise Levels On Board Ships, in Resolution A.468(XII), IMO, Editor. 1981.

[14] NATO, Standardization Agreement (STANAG): Subject: Common Procedures for Seakeeping in the Ship Design Process. 2000: NATO, Military Agency for Standardization.

[15] NORDFORSK, Assessment of Ship Performance in a Seaway. 1987, Copenhagen: Nordforsk. 91 s.

[16] Graham, R., Motion-Induced Interruptions as Ship Operability Criteria. Naval Engineers Journal, 1990. 102(2): p. 65-71.

[17] Rumawas, V. and B.E. Asbjørnslett, Exploratory Surveys of Human Factors on Offshore Supply Vessels in the Norwegian Sea. Naval Engineers Journal, 2013. 125(2).

[18] Rumawas, V., B.E. Asbjørnslett, and C.A. Klöckner, Human Factors Evaluation in Ship Design: A Case Study on Offshore Supply Vessels in the Norwegian Sea, Part I: Theoretical Background and Technical Constructs. Naval engineers journal (Print), 2016. 128(4): p. 81-96.

[19] Rumawas, V., B.E. Asbjørnslett, and C.A. Klöckner, Human Factors Evaluation in Ship Design: A Case Study on Offshore Supply Vessel in the Norwegian Sea, Part II: Multivariate Analyses and Structural Modelling. Naval engineers journal (Print), 2017. 129(1): p. 45-58.

[20] ISO, Mechanical Vibration - Measurement of Vibration on Ships - Part 2: Measurement of Structural Vibration. 2008, The International Organization for Standardization: Geneva, Switzerland.

[21] Colwell, J.L., NATO Questionnaire: Correlation Between Ship Motions, Fatigue, Seasickness and Naval Task Performance, in International Conference Human Factors in Ship Design and Operation. 2000, The Royal Institution of Naval Architects: London.

[22] Rumawas, V., Human Factors in Ship Design and Operation: Experiential Learning. 2016, Norwegian University of Science and Technology. p. 206.

[23] McCauley, M.E., et al., Motion Sickness Incidence: Exploratory Studies of Habituation, Pitch and Roll, and the Refinement of a Mathematical Model. 1976, Santa Barbara, California: Human Factors Research, Inc.

[24] Griffin, M.J., Handbook of human vibration. 1990, London: Academic Press. xvi, 988 s. 